\title{
Prevalence, antimicrobial resistance and
} multiple-locus variable-number tandem-repeat analysis profiles of diarrheagenic Escherichia coli isolated from
different retail foods

Lili Wang, Hiromi Nakamura, Eriko Kage-Nakadai, Yukiko Hara-Kudo, Yoshikazu Nishikawa

\begin{tabular}{|c|l|}
\hline Citation & International Journal of Food Microbiology, 249: 44-52 \\
\hline Issue Date & 2017-05-16 \\
\hline Type & Journal Article \\
\hline Textversion & author \\
\hline \multirow{3}{*}{ Rights } & $\begin{array}{l}\text { C2017 Elsevier B.V. This manuscript version is made available under the } \\
\text { CC-BY-NC-ND 4.0 License. https://creativecommons.org/licenses/by-nc-nd/4.0/. } \\
\text { This is the accept manuscript version. The article has been published in final form } \\
\text { at https://doi.org/10.1016/j.ijfoodmicro.2017.03.003 }\end{array}$ \\
\hline DOI & $10.1016 /$ j.ijfoodmicro.2017.03.003 \\
\hline
\end{tabular}

Self-Archiving by Author(s)

Placed on: Osaka City University

WANG, L., NAKAMURA, H., KAGE-NAKADAI, E., HARA-KUDO, Y., \& NISHIKAWA, Y. (2017). Prevalence, antimicrobial resistance and multiple-locus variable-number tandem-repeat analysis profiles of diarrheagenic Escherichia coli isolated from different retail foods. International Journal of Food Microbiology. 249, 44-52. 
1 Prevalence, antimicrobial resistance and multiple-locus variable-number

2 tandem-repeat analysis profiles of diarrheagenic Escherichia coli isolated from

3 different retail foods

4

$5 \quad$ Lili Wang ${ }^{1,2}$, Hiromi Nakamura ${ }^{3}$, Eriko Kage-Nakadai ${ }^{2}$, Yukiko Hara-Kudo ${ }^{4}$,

6 Yoshikazu Nishikawa ${ }^{2 *}$

7

$8{ }^{1}$ Dalian University of Technology, School of Life Science and Biotechnology, Dalian, 116024,

9 China

$10{ }^{2}$ Osaka City University, Graduate School of Human Life Science, Osaka 558-8585, Japan

$11{ }^{3}$ Department of Microbiology, Osaka City Institute of Public Health and Environmental Sciences,

12 Osaka 543-0026, Japan

$13{ }^{4}$ Division of Microbiology, National Institute of Health Sciences, Tokyo 158-8501, Japan

15 Running head: Discrimination of diarrheagenic Escherichia coli

$17 *$ Author to whom all correspondence and requests for reprints should be addressed: $\mathrm{Y}$.

18 Nishikawa, Graduate School of Human Life Science, Osaka City University, 3-3-138 Sugimoto,

19 Osaka 558-8585, Japan

20 Phone \& Fax: +81-6-6605-2910

21 E-mail: nisikawa@life.osaka-cu.ac.jp 


\section{ABSTRACT}

23 Diarrheagenic E. coli (DEC) isolates were recovered from local retail markets and the Osaka

24 Municipal Central Wholesale Market in Japan. Retail food samples were collected for analysis in

25 Osaka Japan from 2005 to 2008 and consisted of 32 beef, 28 pork, 20 poultry, 136 fish, 66 fruits

26 and vegetables and 51 ready-to-eat (RTE) food samples. A total of 82 DEC strains were

27 recovered from $64(19 \%)$ food samples with the highest prevalence in poultry $(100 \%, 20 / 20)$,

28 followed by pork $(54 \%, 15 / 28)$, beef $(28 \%, 9 / 32)$, fruits and vegetables $(12 \%, 8 / 66)$, fish $(6.6 \%$,

29 9/136) and RTE foods (5.9\%, 3/51). Most of the strains belonged to E. coli possessing the

30 enteroaggregative E. coli (EAEC) heat-stable enterotoxin 1 (EAST1) gene (EAST1EC; n=62,

$31 P<0.0001)$ and enteropathogenic $E$. coli $($ EPEC; $n=16, P<0.01)$, whereas only 1 strain belonged

32 to Shiga toxin-producing E. coli (STEC), 1 to EAEC and 2 to enterotoxigenic $E$. coli (ETEC)

33 strains. Of the 82 DEC isolates, $22 \mathrm{O}$ and $13 \mathrm{H}$ serogroups were detected, including some specific

34 serogroups (O91, O103, O115, O119, O126, and O157) which have been associated with human

35 diarrheal infections. Phylogenetic group A and B1 were predominant among the DEC isolates.

36 Antimicrobial resistance to tetracycline was most common (49\%), followed by nalidixic acid

37 (28\%), ampicillin (24\%), sulfamethoxazole/trimethoprim (20\%), and cephalothin (18\%). All

38 isolates were susceptible to aztreonam. Of the resistant strains, 44\% (22/50) demonstrated

39 resistance to more than 3 antimicrobial agents. Isolates resistant to more than 5 antimicrobials

40 were only found in the meat samples, while isolates from the fruits and vegetables as well as RTE

41 foods showed resistance to only 1 or 2 antimicrobial agents. Sixty one percent of EAST1EC, 56\%

42 of EPEC and all of the EAEC and ETEC were resistant to at least 1 antimicrobial agent.

43 Multiple-locus variable-number tandem repeat analysis (MLVA) was used in this study for

44 genotyping of DEC. The 82 isolates collected for this study showed 77 distinct MLVA profiles 
45 located among 3 branches. The Simpson's Index of Diversity $(D)$ was $99.9 \%$ at its highest. The

46 high diversity of these food strains would suggest their originating from a variety of sources and

47 environments. In conclusion, retail food samples in Japan were contaminated with DEC;

48 EAST1EC, a putative DEC, were detected at high rates in poultry, pork and beef. Isolates

49 resistant to more than 3 antimicrobials were found only in raw meat and fish. Food animals may

50 act as the reservoir for multi-resistant bacteria. Due to the finding that nearly $1 / 3$ of EAST1EC

51 strains were resistant to more than 3 antimicrobials, additional surveillance for EAST1EC should

52 be initiated.

53

54 Keywords: diarrheagenic Escherichia coli, EAST1EC, MLVA, food, antimicrobial resistance 


\section{Introduction}

Escherichia coli are widespread commensal bacteria found in humans and animals and some

of them cause both animal and human infections (Kalita et al., 2014). E. coli causing intestinal

58 diseases have been categorized as diarrheagenic E. coli (DEC) and classified into six well-

59 described categories including EPEC, STEC or enterohemorrhagic E. coli (EHEC), ETEC,

60 EAEC, enteroinvasive E. coli (EIEC) and diffusely adherent E. coli (DAEC) (Kaper et al., 2004).

61 The ast $A$ gene encoding EAEC heat-stable enterotoxin 1 (EAST1) was initially detected in

62 EAEC (Nataro and Kaper, 1998) and subsequently has been detected quite frequently in other

63 DEC pathotypes including EPEC, ETEC, and EHEC (Kameyama et al., 2015; Sirikaew, 2014;

64 Wang et al., 2013). Although the role of EAST1 in human disease still remains to be clarified,

65 EAST1EC, defined as an E. coli possessing only the ast A as a possible virulence gene, has been

66 implicated in several outbreaks (Nishikawa et al., 1999; Zhou et al., 2002).

67 Food borne diseases are an important public health problem not only in developing countries

68 but also in developed countries. Numerous outbreaks have been reported to the national

69 surveillance and reporting systems of many countries (Crowe et al., 2015; Inatsu et al., 2015;

70 Moon et al., 2014). Animal meat and dairy products can be easily contaminated by E. coli during

71 slaughter and subsequent handling. Numerous studies have revealed that animal meat and dairy

72 products are important transmission routes of DEC to cause human infections. DEC strains were

73 present on 2.84 and $0.75 \%$ of dairy products and meat products including beef, pork goat, lamb

74 meat and poultry, respectively (Canizalez-Roman et al., 2013). Additionally, raw fish such as

75 Sushi and ready-to-eat (RTE) foods are consumed without further cooking which is considered to

76 be a potential risk because of contamination by microorganisms during processing and storage

77 (Jain et al., 2008; Terajima et al., 1999; Yu et al., 2016). Furthermore, food borne disease 
78 outbreaks associated with fresh fruits and vegetables, especially leafy green vegetables, have

79 been increasing in occurrence worldwide (Herman et al., 2015; Hyde R. 2011; Kozak et al., 80 2013).

81 According to our previous studies, EPEC and EAST1EC are frequently isolated from 82 diarrheal patients (Nishikawa et al., 2002) and are most prevalent among healthy individuals

83 (Fujihara et al., 2009) and domestic animals (unpublished data). These bacteria seem to play 84 important roles in the cause of sporadic diarrheal illnesses. However, the transmission routes of 85 foodborne DEC have not yet been clarified. The aim of this study was to reveal the current 86 condition of DEC contamination in Japanese retail food products and the possible role of food 87 acting as a vehicle for the pathogens, particularly EPEC and EAST1EC, based on the prevalence 88 of antimicrobial resistance and their phylogenetic relationship. To the knowledge, this is the first

89 survey concerned with the extensive isolation of DEC strains from various Japanese food

90 products, including poultry, pork, beef, fruits and vegetables, fish and RTE foods.

91

92 2. Materials and methods

\section{2.1. Sampling and DEC isolation}

94 A total of 333 food samples (136 fish, 66 fruit and vegetables, 51 RTE foods, 32 beef, 28 pork

95 and 20 poultry samples) were obtained from local retail markets and the Osaka Municipal Central

96 Wholesale Market in Osaka, Japan from 2005 to 2008. The samples were transported in a cooling

97 bag and examined immediately after arrival at the laboratory. Food samples $(10 \mathrm{~g})$ were

98 homogenized in $90 \mathrm{ml}$ of Brain Heart Infusion Broth (BHI, Nissui Pharmaceutical Company,

99 Tokyo, Japan) using a Masticator (IUL Instrument, Barcelona, Spain). The BHI was then

100 decanted into a $200 \mathrm{ml}$ Erlenmeyer Flask through a paper strainer attached to a Stomacher bag, 
101 and then incubated for $3 \mathrm{~h}$ at $37^{\circ} \mathrm{C}$ to resuscitate damaged cells. The cultured BHI was transferred

102 to a $500 \mathrm{ml}$ flask and mixed with an equal amount of double-strength Tryptone Phosphate Broth

103 (TP, prepared according to the FDA manual), and the mixture was then incubated for $20 \mathrm{~h}$ at

$10444^{\circ} \mathrm{C}$ in a water bath. This enrichment broth was streaked onto Tricolor Agar Plates (Elmex,

105 Tokyo, Japan) and/or Eosin Methylene Blue Plates (EMB, Nissui) to assess the presence of

106 coliform and fecal E. coli. Enrichment broth cultures were screened for the 7 pathogenic E. coli

107 (EPEC (eae), STEC (stx1, stx2), ETEC (elt, est for STh and est for STp), EIEC (virB), EAEC

$108(\operatorname{agg} R)$, EAST1EC $(a s t A)$, and DAEC $(a f a B))$ by the Multiplex Real-Time PCR method (Hidaka

109 et al., 2009), and DEC strains were isolated by the previously developed HGMF-Colony

110 Hybridization method (Wang et al., 2011).

\section{2.2. Serotyping}

112 Eighty-two DEC isolates (62 EAST1EC, 16 EPEC, 2 ETEC, 1 STEC and 1 EAEC) were

113 serotyped with 50 specific $\mathrm{O}$ antisera and 22 specific $\mathrm{H}$ antisera designed for pathogenic E. coli

114 (Denka Seiken Company, Tokyo, Japan), according to the manufacturer's protocol, and the

115 bacterial motility was confirmed using the method described by Arikawa et al. (2010). Isolates

116 that did not react with any of the $\mathrm{O}$ and $\mathrm{H}$ antisera examined were classified as OUT $(\mathrm{O}$ antisera

117 untypeable) and HUT (H antisera untypeable), and non-motile strains were denoted as HNM

118 (non-motile).

119

120 2.3. Phylogenetic group determination

121 Eighty-two DEC strains were classified into the four major phylogenetic groups (A, B1, B2,

122 or D) as proposed by Clermont et al. (2000) based on the presence or absence of the genes chuA

123 and yjaA and the DNA fragment tspE4C2 determined using a two-step triplex PCR protocol. 


\section{2.4. Antimicrobial susceptibility testing}

126 Antimicrobial susceptibility testing to 12 antimicrobials was carried out in the 82 DEC

127 isolates by the Disk Diffusion Method on Mueller Hinton II Agar (Becton Dickinson, Franklin

128 Lakes, NJ). The standard procedure of the Clinical and Laboratory Standards Institute (CLSI)

129 M100-S25 (CLSI, 2015) was followed throughout the testing procedure.

130 The concentration of the disks (Becton Dickinson, Franklin Lakes, NJ) and the abbreviations

131 of the antimicrobial agents which were used throughout this study are amoxicillin/clavulanic acid

132 (AMC: 20/10 $\mu \mathrm{g}$ ), ampicillin (AMP: $10 \mu \mathrm{g}$ ), aztreonam (ATM: $30 \mu \mathrm{g}$ ), cefoxitin (FOX: $30 \mu \mathrm{g}$ ),

133 ceftriaxion (CRO: $30 \mu \mathrm{g}$ ), cephalothin (CEP: $30 \mu \mathrm{g}$ ), chloramphenicol (CHL: $30 \mu \mathrm{g}$ ),

134 ciprofloxacin (CIP: $5 \mu \mathrm{g}$ ), gentamicin (GEN: $10 \mu \mathrm{g}$ ), nalidixic acid (NAL: $30 \mu \mathrm{g}$ ),

135 sulfamethoxazole/trimetroprim (SXT: 23.75/1.25 $\mu \mathrm{g}$ ) and tetracycline (TET: $30 \mu \mathrm{g}$ ). The isolates

136 were classified as susceptible, intermediate, or resistant according to the zone diameter

137 interpretative standard recommendations by CLSI-M100-S25. Confirmation of ESBL production

138 was carried out by the Combination Disc Diffusion Test with clavulanic acid (CLSI-M100-S25,

139 2015) while AmpC DEC production was confirmed according to the description in a previous

140 study (Yagi et al., 2005).

141

142 2.5. Multiple-locus variable-number tandem-repeat analysis (MLVA) typing

143 The relationship among the DEC strains was determined by exploring polymorphisms in 10

144 variable-number tandem repeat (VNTR) loci, and primers were constructed in order to amplify

145 the targets in all species where the loci were present as described by Lindstedt et al. (2007) and

146 Løbersli et al. (2012). The PCR reactions were performed with GoTaq Flexi DNA Polymerase 
148 Biosystems, Cape Town, South Africa) according to the manufacturer's recommendations and the 149 previous description (Lindstedt et al., 2007; Løbersli et al., 2012). After the PCR amplifications,

150 samples were prepared for capillary electrophoresis on an ABI-3130 Genetic Analyzer (Applied

151 Biosystems, Foster City, CA) as described by Lindstedt et al. (2007) and Løbersli et al. (2012).

\subsection{Proposed allele designations}

154 For each locus, the following formulae were varied in order that the strains gave the best 155 conversion to actual repeat numbers: CVN001: ([OP (observed PCR product size)+3]-250)/39, 156 CVN002: (OP-272)/18, CVN003: (OP-404)/15, CVN004: (OP-231)/15, CVN007:

157 (OP-314)/18, CVN014: ([OP+2]-111)/6, CVN015:(OP-189)/6, CCR001: (OP-131)/59,

158 CVN016: $([\mathrm{OP}+2]-478) / 6$ and CVN017: $([\mathrm{OP}+3]-202) / 6$. To best fit the data, all VNTR repeat

159 numbers were rounded to the nearest whole repeat, while the CRISPR repeat numbers were

160 rounded down to the nearest full repeat as described by Lindstedt et al. (2007) and Løbersli et al.

161 (2012). Absence of PCR product is designated with a negative number ( -2$)$, and zero (0) is used

162 to describe a positive PCR product containing no repeats. The results are always reported in the

163 following order: CVN001, CVN002, CVN003, CVN004, CVN007, CVN014, CVN015,

164 CCR001, CVN016 and CVN017. All Dendrograms and Minimum Spanning Trees (MST) were

165 constructed using BioNumerics Version 5.10 (Applied Maths, Saint-Martens-Latem, Belgium).

$167 \quad 2.7$ Statistics

168 The differences between the DEC strains isolated from the different food sources were tested 169 for significance by performing a Chi-squared Test with Fisher's Exact Probability Test. Simpson's 
170 Index of Diversity $(D)$ was calculated according to the formulas described by Hunter and Gaston 171 (1988).

172

\section{3. Results}

174 3.1. DEC detection and isolation from food samples

175 A total of 82 DEC strains were isolated from 333 food samples. Overall, $19 \%(n=64)$ of the 176333 samples were positive for DEC (Table 1). The isolation rate from poultry was significantly

177 higher than those from other types of food samples $(P<0.0002)$. Similarly, DEC isolates were

178 more prevalent among pork than fish, fruits and vegetables and RTE foods samples $(P<0.0001)$.

179 Beef samples showed a higher DEC isolation rate than fish and RTE food samples $(P<0.01)$.

180 Most of the strains isolated from the 333 food samples belonged to EAST1EC ( $\mathrm{n}=62, P<0.0001$ )

181 and EPEC ( $\mathrm{n}=16, P<0.01$ ), whereas only 1 belonged to STEC, 1 to EAEC and 2 to ETEC strains.

3.2. Prevalence of serotypes

184 Of the 82 DEC isolates, 24 (29\%) strains didn't respond to any of the $\mathrm{O}$ and $\mathrm{H}$ antisera, and 185 the remaining isolates belonged to $22 \mathrm{O}$ and $13 \mathrm{H}$ serogroups (Table 2 and Fig. 1). In the $31 \mathrm{O}-$ 186 identifiable strains, O8 (four strains) and O18 (four strains) were the most frequent serogroups,

187 followed by O91, O103 and O126 with 2 strains each while 1 strain each was detected in the 188 other $17 \mathrm{O}$ serogroups. In contrast, H16, H12, H6, H9, H34 and H40 were identified in 12, 9, 3, 1893 3, 3, and 3 DEC isolates of $44 \mathrm{H}$-discriminable strains, respectively. Interestingly, 1 EAST1EC 190 isolate from pork responded to both $\mathrm{O} 20$ and $\mathrm{O} 157$ antisera.

\subsection{Phylogenetic grouping}


193 Phylogenetic grouping of the 82 DEC isolates showed that $37(45 \%), 27(33 \%), 5(6.1 \%)$, and

$19413(16 \%)$ belonged to the phylogenetic groups A, B1, B2 and D, respectively, as shown in Table

195 3. Phylogenetic group A was predominant among EAST1EC (50\%), while group B1 was

196 prevalent in EPEC (38\%), and all of the pathogenic strains of STEC, EAEC and ETEC belonged

197 to the phylogroups A and B1. Phylogenetic group A was predominant among almost 50\% of the

198 strains obtained from beef (45\%), pork (50\%), poultry (54\%) and RTE foods (50\%), while group

199 B1 was most prevalent in fish (38\%) and fruit and vegetable (50\%) samples (date not shown). No

200 B2 strains were isolated from beef, poultry or RTE samples. Statistically significant differences

201 were not obtained in the distribution of phylogenetic groups among the isolates from each food 202 source.

\subsection{Antimicrobial susceptibility testing}

205 A total of $50(61 \%)$ isolates from the food samples were resistant to at least 1 antimicrobial 206 agent, while $32(39 \%)$ isolates were sensitive to all the 12 antimicrobials tested in this study

207 (Table 4). Poultry isolates showed a higher resistant rate than pork $(P<0.05)$ and fish $(P<0.01)$.

208 Antimicrobial resistant strains were significantly more prevalent in poultry $(P<0.001)$ and pork $209(P<0.05)$ samples than fruits and vegetables.

210 Resistance was observed to TET (49\%), NAL (28\%), AMP (24\%), SXT (20\%), and CEP

211 (18\%) as shown in Table 5. A low prevalence of resistance (from 1.2 to $7.3 \%$ of strains) was

212 detected for the remaining agents and no ATM resistant strains were detected in the DEC isolates

213 in this study. The poultry isolates had the greatest resistance to TET ( $77 \%, P<0.001)$, followed by

214 beef (55\%,P<0.05), pork (50\%, P<0.05), RTE foods (50\%) and fish $(15.4 \%)$ while no TET

215 resistant strains were isolated from fruits and vegetables. A significant difference in TET resistant 
216 properties was also observed between strains isolated from poultry and fish $(P<0.001)$. Similarly,

$2176(55 \%)$ isolates from beef and $14(54 \%)$ isolates from poultry were resistant to NAL and both of

218 these were significantly higher than the isolates obtained from fish (7.7\%), pork (5\%) and fruits

219 and vegetables $(0 \%)$ with $P$ values of $P<0.05$. Additionally, significant differences in SXT

220 resistant properties were observed between strains isolated from pork and fish $(P<0.05)$.

221 Only $30 \%$ of the drug resistance strains (15/50) were resistant to only 1 antimicrobial agent

222 (Table 4), while 35 (70\%) showed multi-resistance (resistance to 2 or more antimicrobials). The

223 highest degree of resistance was exhibited by an EAST1EC strain in a beef sample, which was

224 resistant to 9 antimicrobial agents. Most of the drug resistant strains from beef $(5 / 7,71 \%)$ and

225 fish $(3 / 5,60 \%)$ were resistant to more than 3 antimicrobial agents. Isolates resistant to more than

2265 antimicrobials were only found in meat samples, while isolates from fruits and vegetables and

227 RTE foods showed resistance to only 1 or 2 antimicrobial agents.

228 ESBL and AmpC Producing Conformation Tests were performed for 3 DEC strains (1

229 EAST1EC from poultry and beef, and the EAEC from fish), which are marked with underline in

230 Fig 1. Two EAST1EC strains showed the results for ESBL minus but AmpC plus, including the

231 one which displayed the highest degree of resistance to 9 antimicrobial agents.

232 From the point of view of DEC pathotypes, $61 \%$ of EAST1EC, $56 \%$ of EPEC and all of the

233 EAEC and ETEC were resistant to at least 1 antimicrobial agent (Table 6). However, the only 1

234 STEC, which was positive for stx2, wasn't resistant to any of the antimicrobials tested. About

$23531 \%$ of EAST1ECs were resistant to more than 3 antimicrobials. In contrast, ETEC strains and a

236 high rate of $44 \%$ EPEC strains showed resistance to 1 or 2 antimicrobials. The only 1 EAEC

237 strain was resistant to 4 antimicrobials.

238 Combined with the results of phylogenetic grouping (Table 7), antimicrobial resistant strains 
239 were prevalent in the phylogenetic groups D (69\%), A (68\%) and B1 (56\%). However, only 1

240 resistant strain was recognized in group B2. All group A and B1 strains from poultry were

241 resistant to 1 or more antimicrobials; except for 1 EAST1EC strain in group A (Table 4 and 7).

3.5. Multiple-locus variable-number tandem-repeat analysis (MLVA) typing

MLVA typing divided the 82 DEC strains into 78 distinct profiles with 74 of unique and four pairs of identical MLVA loci pattern marked in black squares, indicating high polymorphism in the samples tested (Fig. 1). The resolution for DEC isolates was determined by GECM10 Assay with a Simpson's Index of Diversity $(D)$ value of $99.9 \%$. The isolates could be principally discriminated by alleles of locus CVN014 $(D=90.3 \%)$, followed by those of loci CVN016 $(D=$ $69.9 \%)$ and CVN001 $(D=68.2 \%)$.

The MLVA typing was independent from the serotyping since 12 strains of serogroup H16, 9 of H12, 4 each of $\mathrm{O} 8$ and $\mathrm{O} 18$, and $2 \mathrm{O} 126$ strains were widely scattered on the dendrogram

252 (Table 2 and Fig. 1). Ten of 16 EPEC strains centered around 2 adjacent regions. Four pairs of 253 isolates were assigned to the same MLVA types. Two pairs consisted of isolates of the same $\mathrm{O}$

254 serogroup or the virogroup ETEC. However, 1 pair was composed of an EAST1EC strain 255 obtained from fruits and vegetables and 1 STEC strain obtained from beef.

256 A Minimum Spanning Tree (MST) was constructed to investigate the phylogenetic

257 relationship of the 82 food-borne DEC isolates in Fig. 2. The central stem strain marked in the 258 red circle belonged to EAST1EC, which was isolated from a beef sample and resistant to 9

259 antimicrobial agents. Two fish, 1 pork and 1 fruit and vegetable isolates were branched in the 260 distinctly green group clearly separated from the other isolates. The strains which demonstrated 261 resistance to 1 or 2 antimicrobials were prevalent in the periphery of the MST, while multi-drug 
262 resistant strains were more predominant near the central branch with the core (red circle) of a 9-

263 antimicrobial resistant strain from beef, although some of the strains were located outwards from

264 the core.

\section{Discussion}

267 The epidemiological properties of 82 DEC strains from 333 food samples were examined to 268 determine the risk of foods being used as a vehicle for transmission by DEC. The prevalence of

269 DEC was 6.0\% (20/333) in this study (Table 1), which did not include EAST1EC because the

270 enterovirulence was not confirmed yet. This rate was higher than that reported from Mexico

271 (1.1\%) (Canizalez-Roman et al., 2013), Iran (4.0\%) (Mazaheri et al., 2014) and Colombia (2.1\%)

272 (Amézquita-Montes et al., 2015), although higher prevalence (45\%) than this study $(30 \%, 6 / 20)$

273 in poultry has been reported from Finland (Kagambèga et al., 2012). These results suggested that

274 the higher DEC isolation rate observed in this study may not necessarily imply serious DEC

275 contamination in food in Japan, but rather, the efficient isolation procedure (colony hybridization)

276 used (Wang et al., 2011) might have contributed to the relatively higher recovery of the DEC

277 strains.

278 All the $82 \mathrm{DEC}$ strains were analyzed for $\mathrm{O}$ and $\mathrm{H}$ antigens. Although the isolates of

279 EAST1EC and EPEC belonged to various $\mathrm{O}$ and $\mathrm{H}$ groups, most of them did not belong to the

280 epidemiologically important O serogroups. However, some EPEC strains were identified as O103

281 and O115, which have been reported to be clinically important serogroups and are associated

282 with outbreaks of gastroenteritis (MacDonald et al., 2012; Saito et al., 2005), and some

283 EAST1EC strains were recognized as O119, O126, and O157, which are considered to be

284 specific serotypes of EPEC or STEC (Kobayashi et al., 2013; Tozzoli et al., 2014). The only 
STEC isolated from beef in the present investigation was serotype O91:H21. The only EAEC

286 strain isolated from fish was serotype O126: HUT, which contains the heat stable enterotoxin

287 gene astA and is usually found among EAEC that cause diarrhea in humans (Silva et al., 2014).

288 The serotyping results of the 2 ETEC isolates in this study revealed that a strain from poultry was 289 untypeable, while the ETEC isolated from a RTE food sample was serotype O127a: HUT that 290 was reportedly associated with a food poisoning outbreak in China (Hao et al., 2012). Therefore,

291 a few DEC stains isolated from this study with specific O serogroups appeared to be potentially

292 harmful to consumers. Additionally, phylogenetic grouping could be effective for assessing the

293 pathogenicity of these strains further. All hemolytic uremic syndrome (HUS)-associated STEC

294 strains (Haugum et al., 2014) and more than half of the EPEC strains (Staples et al., 2013; Wang

295 et al., 2013) isolated from diarrhea patients are from the phylogroup B1. Phylogenetic grouping

296 examined in this study and other surveys indicated that group A and B1 were predominant among

297 the DEC isolates from foods, consistent with the findings reported by previous studies (Koo et

298 al., 2012; Siriwan-Sirikaew et al., 2015; Ombarak et al., 2016). The same results have also been

299 found in the studies of domestic animals (Ishii et al., 2007; Coura et al., 2015). It is suggested that

300 DEC, especially the group B1 of EPEC, contaminating food products might have a potential of 301 intestinal infection.

302 Antimicrobial susceptibility testing of isolates by the Disc Diffusion Method indicated that 303 DEC isolated from foods in this study showed a high resistant rate of $61 \%(50 / 82)$, while $43 \%$ $304(35 / 82)$ of the DEC strains were resistant to multiple antimicrobial agents. Similar results were 305 reported from Mexico (Canizalez-Roman et al., 2013; Gómez-Aldapa et al., 2016) Greece

306 (Solomakos et al., 2009) and Thailand (Siriwan-Sirikaew et al., 2015) with the high resistant rate 307 of $66-100 \%$. Resistances to TET, AMP, and SXT among DEC strains isolated from food samples 
308 are also common in other reports (Canizalez-Roman et al., 2013; Teophilo et al., 2002). Despite

309 the high isolation rates in chicken (Abdallah et al., 2015; Pacholewicz et al., 2015), no ESBL

310 producing E. coli was found in this study. However, EAST1EC showed a high multi-drug

311 resistant rate of $31 \%$ (more than 3 antimicrobials) including 2 strains of AmpC-producing

312 EAST1EC. Since EAST1EC has been associated with outbreaks in Japan (Nishikawa et al., 1999;

313 Zhou et al., 2002; Ishiguro et al., 2005), foodborne EAST1EC could be important not only as an

314 enteric pathogen, but also as a source of the resistance genes.

315 The phylogenetic group D strains showed the highest antimicrobial resistant rate of $69 \%$

316 (9/13), although the isolation rate (16\%) of the DEC of group D was lower than groups A (45\%)

317 and B1 (33\%). The level of resistance to different antimicrobials varied according to the source

318 of the isolates and phylogenetic grouping. DEC isolates from meat and poultry showed a higher

319 resistance rate than those from other sources, which might be due to the common use of

320 antimicrobials for the prevention and treatment of diseases in the animals in which the food have

321 come from (Canizalez-Roman et al., 2013).

322 The phylogenetic relationship and the distance of the 82 DEC isolates in this study were

323 further discriminated by the GECM10 assay of Lindstedt et al. (2007) and Løbersli et al. (2012)

324 and the $D$ value reached $99.9 \%$. Similarly, diversity index values as high as $97 \%$ and $96 \%$ for the

325 GECM10 assay was observed in Argentina in a set of 72 non-O157:H7 VTEC isolates analyzed

326 (González et al., 2014) and 32 shigatoxin-producing E. coli O26:H11 strains isolated from

327 animals, food and clinical samples (Krüger et al., 2015), respectively. The high $D$ values

328 observed in this study and previous reports suggest the sufficient discriminating power for the

329 GECM10 assay in DEC epidemiological surveys. The isolates could be principally discriminated

330 by the alleles of the locus CVN014 $(D=90.3 \%)$, CVN016 $(D=69.9 \%)$ and CVN001 $(D=$ 
$33168.2 \%$ ), which also reconfirmed the primary discrimination power in previous reports (González

332 et al., 2014; Krüger et al., 2015). The high diversity of DEC strains found in the current study

333 suggested that these contaminating bacteria may have come from a variety of sources and

334 environments. Multiple DEC strains could be transferred through food manufacturing,

335 transportation and handling processes. Four pairs of isolates presented identical MLVA loci

336 pattern (Fig. 1), suggesting that these are sets of homologous strains isolated from different

337 sources. However, 1 pair was composed of different pathotypes of DEC (EAST1EC and STEC).

338 Similar results were also reported in a raw milk and raw milk cheese analyzed by PFGE in Egypt

339 (Ombarak et al., 2016). The distribution of strains in MST was independent of the food sample

340 (Fig. 2).

341 In conclusion, retail food samples in Japan could be contaminated with DEC, particularly

342 EAST1EC and EPEC, and high contamination rates were observed in poultry, pork and beef. It is

343 suggested that fur and gastrointestinal tracts of pre-slaughter animals, especially chicken might

344 carry a great number of bacteria. In addition, multiple antimicrobial resistances were among DEC

345 isolated from retail foods, especially meat samples; food animals should act as the reservoir for

346 multi-resistant bacteria. The prevalence of EAST1EC and EPEC among human including healthy

347 carriers must be a reflection of their prevalence in foods. The finding that nearly $1 / 3$ of

348 EAST1EC being resistant to more than 3 antimicrobials suggests that EAST1EC is presumably

349 worth being monitored nevertheless the diarrheagenicity has not been recognized yet.

\section{Acknowledgments}

352 This study was partially supported by a grant from the Ministry of Health, Labour and

353 Welfare of Japan, and a Follow-up Research Fellowship of the Japanese Student Services 
354 Organization.

355 


\section{References}

357 Abdallah H.M., Reuland E.A., Wintermans B.B., Al Naiemi N., Koek A., Abdelwahab A.M., 358 Ammar A.M., Mohamed A.A., Vandenbroucke-Grauls C.M., 2015. Extended-spectrum $\beta$ 359 lactamases and/or carbapenemases-producing enterobacteriaceae isolated from retail chicken 360 meat in Zagazig, Egypt. PLoS One. 10: e0136052.

361 Amézquita-Montes Z., Tamborski M., Kopsombut U.G., Zhang C., Arzuza O.S., Gómez-Duarte

362 O.G., 2015. Genetic relatedness among Escherichia coli pathotypes isolated from food

363 products for human consumption in Cartagena, Colombia. Foodborne. Pathog. Dis. 12, 454-

$364 \quad 461$.

365 Arikawa K., Nishikawa Y., 2010. Interleukin-8 induction due to diffusely adherent Escherichia

366 coli possessing Afa/Dr genes depends on flagella and epithelial Toll-like receptor 5.

367 Microbiol. Immunol. 54, 491-501.

368 Canizalez-Roman A., Gonzalez-Nuñez E., Vidal J.E., Flores-Villaseñor H., León-Sicairos N.,

369 2013. Prevalence and antibiotic resistance profiles of diarrheagenic Escherichia coli strains

370 isolated from food items in northwestern Mexico. Int. J. Food Microbiol. 164, 36-45.

371 Clermont O., Bonacorsi S., Bingen E., 2000. Rapid and simple determination of the Escherichia

372 coli phylogenetic group. Appl. Environ. Microbiol. 66, 4555-4558.

373 Clinical and Laboratory Standards Institute, 2015. Performance Standards for Antimicrobial

374 Susceptibility Testing. CLSI Document M100-S25. Clinical and Laboratory Standards

375 Institute, Wayne, PA.

376 Coura F.M., Diniz Sde A., Silva M.X., Mussi J.M., Barbosa S.M., Lage A.P., Heinemann M.B.,

377 2015. Phylogenetic group determination of Escherichia coli isolated from animals

378 samples. ScientificWorld Journal. 2015, 299-304. 
379 Crowe S.J., Mahon B.E., Vieira A.R., Gould L.H., 2015. Vital Signs: Multistate Foodborne

380 Outbreaks - United States, 2010-2014. MMWR. Morb. Mortal. Wkly. Rep. 64, 1221-1225.

381 Fujihara S., Arikawa K., Aota T., Tanaka H., Nakamura H., Wada T., Hase A., Nishikawa, Y.,

382 2009. Prevalence and properties of diarrheagenic Escherichia coli among healthy individuals

383 in Osaka City, Japan. Jpn. J. Infect. Dis. 62, 318-323.

384 Gómez-Aldapa C.A., Cerna-Cortes J.F., Rangel-Vargas E., Torres-Vitela M.R., Villarruel-López

385 A., Gutiérrez-Alcántara E.J., Castro-Rosas J., 2016. Presence of multidrug-resistant Shiga

386 toxin-producing Escherichia coli, Enteropathogenic E. coli and Enterotoxigenic E. coli, on

387 Raw Nopalitos (Opuntia ficus-indica L.) and in Nopalitos salads from local retail markets in

388 Mexico. Foodborne Pathog. Dis. 13, 269-274.

389 González J., Sanso A.M., Lucchesi P.M., Bustamante A.V., 2014. Comparison of 2 proposed

390 MLVA protocols for subtyping non-O157:H7 verotoxigenic Escherichia coli. Diagn.

$391 \quad$ Microbiol. Infect. Dis. 78, 328-332.

392 Hao R., Qiu S., Wang Y., Yang G., Su W., Song L., Zhang J., Chen J., Jia L., Wang L., Song H.,

393 2012. Quinolone-resistant Escherichia coli O127a:K63 serotype with an extended-spectrum-

394 beta-lactamase phenotype from a food poisoning outbreak in China. J. Clin. Microbiol. 50, $395 \quad 2450-2451$.

396 Haugum K., Johansen J., Gabrielsen C., Brandal L.T., Bergh K., Ussery D.W., Drabløs F., Afset

397 J.E., 2014. Comparative genomics to delineate pathogenic potential in non-O157 Shiga toxin-

398 producing Escherichia coli (STEC) from patients with and without haemolytic uremic

399 syndrome (HUS) in Norway. PLoS One. 9, e111788.

400 Herman K.M., Hall A.J., Gould L.H., 2015. Outbreaks attributed to fresh leafy vegetables, United

401 States, 1973-2012. Epidemiol. Infect. 143, 3011-3021. 
Hidaka A., Hokyo T., Arikawa K., Fujihara S., Ogasawara J., Hase A., Hara-Kudo Y., Nishikawa Y., 2009. Multiplex real-time PCR for exhaustive detection of diarrhoeagenic Escherichia coli. J. Appl. Microbiol. 106, 410-420.

Hunter P.R., Gaston MA., 1988. Numerical index of the discriminatory ability of typing systems: An application of Simpson's index of diversity. J. Clin. Microbiol. 26, 2465-1466.

Hyde R, 2011. Germany reels in the wake of $E$ coli outbreak. Lancet. 377, 1991.

408 Inatsu Y., Ohata Y., Nakamura N., Hosotani Y., Ananchaipattana C., Bari M.L., Kawasaki S., 409 2015. Survival of inoculated Escherichia coli O157:H7 in Japanese Sweet Dumplings during $410 \quad$ storage. Biocontrol. Sci. 20, 285-290.

411 Ishiguro F., Kyota Y., Mochizuki M., Horikawa T., 2005. An outbreak of diarrhea caused by 412 Escherichia coli serogroup O169:HNM harboring a coding gene for enteroaggregative E. coli 413 heat-stable enterotoxin 1 (astA) in Fukui Prefecture. Jpn. J. Infect. Dis. 58, 119-20.

414 Ishii S., Meyer K.P., Sadowsky M.J., 2007. Relationship between phylogenetic groups, genotypic 415 clusters, and virulence gene profiles of Escherichia coli strains from diverse human and 416 animal sources. Appl. Environ. Microbiol. 73, 5703-5710.

417 Jain S., Chen L., Dechet A., Hertz A.T., Brus D.L., Hanley K., Wilson B., Frank J., Greene K.D., 418 Parsons M., Bopp C.A., Todd R., Hoekstra M., Mintz E.D., Ram P.K., 2008. An outbreak of 419 enterotoxigenic Escherichia coli associated with sushi restaurants in Nevada, 2004. Clin. $420 \quad$ Infect. Dis. 47, 1-7.

421 Kalita A., Hu J., Torres A.G., 2014. Recent advances in adherence and invasion of pathogenic 422 Escherichia coli. Curr. Opin. Infect. Dis. 27, 459-464.

423 Kagambèga A., Barro N., Traoré A.S., Siitonen A., Haukka K., 2012. Characterization of 424 Salmonella enterica and detection of the virulence genes specific to diarrheagenic 

Dis. $9,589-593$.

427 Kameyama M., Yabata J., Nomura Y., Tominaga K., 2015. Biochemical features and virulence 428 gene profiles of non-O157/O26 Enterohemorrhagic Escherichia coli strains from humans in 429 the Yamaguchi Prefecture, Japan. Jpn. J. Infect. Dis. 68, 216-220.

430 Kaper J.B., Nataro J.P., Mobley H.L., 2004. Pathogenic Escherichia coli. Nat. Rev. Microbiol. 2, $431 \quad 123-140$.

432 Kobayashi N., Lee K., Yamazaki A., Saito S., Furukawa I., Kono T., Maeda E., Isobe J., Sugita433 Konishi Y., Hara-Kudo Y., 2013. Virulence gene profiles and population genetic analysis for 434 exploration of pathogenic serogroups of Shiga toxin-producing Escherichia coli. J. Clin. $435 \quad$ Microbiol. 51, 4022-4028.

436 Koo H.J., Kwak H.S., Yoon S.H., Woo G.J., 2012. Phylogenetic group distribution and 437 prevalence of virulence genes in Escherichia coli isolates from food samples in South Korea. $438 \quad$ World. J. Microbiol. Biotechnol. 28, 1813-1816.

439 Kozak G.K., MacDonald D., Landry L., Farber J.M., 2013. Foodborne outbreaks in Canada $440 \quad$ linked to produce: 2001 through 2009. J. Food Prot. 76, 173-183.

441 Krüger A., Lucchesi P.M., Sanso A.M., Etcheverría A.I., Bustamante A.V., Burgán J., Fernández 442 L., Fernández D., Leotta G., Friedrich A.W., Padola N.L., Rossen J.W., 2015. Genetic 443 characterization of Shiga toxin-producing Escherichia coli O26:H11 strains isolated from 444 animal, food, and clinical samples. Front. Cell. Infect. Microbiol. 5, 74.

445 Lindstedt B.A., Brandal L.T., Aas L., Vardund T., Kapperud G., 2007. Study of polymorphic 446 variable-number of tandem repeats loci in the ECOR collection and in a set of pathogenic 447 Escherichia coli and Shigella isolates for use in a genotyping assay. J. Microbiol. Methods. 
69, 197-205.

449 Løbersli I., Haugum K., Lindstedt B.A., 2012. Rapid and high resolution genotyping of all

450 Escherichia coli serotypes using 10 genomic repeat-containing loci. J. Microbiol. Methods.

$451 \quad 88,134-139$.

452 MacDonald E., Dalane P.K., Aavitsland P., Brandal L.T., Wester A.L., Vold L., 2012. Implications

453 of screening and childcare exclusion policies for children with Shiga-toxin producing

454 Escherichia coli infections: Lessons learned from an outbreak in a daycare centre, Norway.

455 BMC Infect. Dis. 14, 673.

456 Mazaheri S., Salmanzadeh-Ahrabi S., Falsafi T., Aslani M.M., 2014. Isolation of

457 Enteropathogenic Escherichia coli from lettuce samples in Tehran. Gastroenterol. Hepatol.

$458 \quad$ Bed. Bench. 7, 38-42.

459 Moon S., Sohn I.W., Hong Y., Lee H., Park J.H., Kwon G.Y., Lee S., Youn S.K., 2014. Emerging

460 pathogens and vehicles of food- and water-borne disease outbreaks in Korea, 2007-2012.

461 Osong. Public Health. Res. Perspect. 5, 34-39.

462 Nataro J.P., Kaper J.B., 1998. Diarrheagenic Escherichia coli. Clin. Microbiol. Rev. 11, $142-201$.

463 Nishikawa Y., Ogasawara J., Helander A., Haruki K., 1999. An outbreak of gastroenteritis in

464 Japan due to Escherichia coli O166. Emerg. Infect. Dis. 5, 300.

465 Nishikawa Y., Zhou Z., Hase A., Ogasawara J., Kitase T., Abe N., Nakamura H., Wada T., Ishii

466 E., Haruki K., the Surveillance Team., 2002. Diarrheagenic Escherichia coli isolated from

467 stools of sporadic cases of diarrheal illness in Osaka City, Japan between 1997 and 2000:

468 prevalence of enteroaggregative E. coli heat-stable enterotoxin 1 gene-possessing E. coli. Jpn.

$469 \quad$ J. Infect. Dis. 55, 183-190.

470 Ombarak R.A., Hinenoya A., Awasthi S.P., Iguchi A., Shima A., Elbagory A.R., Yamasaki S., 

2016. Prevalence and pathogenic potential of Escherichia coli isolates from raw milk and raw milk cheese in Egypt. Int. J. Food Microbiol. 221, 69-76.

473 Pacholewicz E., Liakopoulos A., Swart A., Gortemaker B., Dierikx C., Havelaar A., Schmitt H.,

474 2015. Reduction of extended-spectrum- $\beta$-lactamase- and AmpC- $\beta$-lactamase-producing 475 Escherichia coli through processing in two broiler chicken slaughterhouses. Int. J. Food $476 \quad$ Microbiol. 215, 57-63.

477 Saito N., Kawano M., Kobayashi T., Watanabe S., Yamada W., Yatsu J., Kawamukai K., Akiyama 478 K., 2005. An outbreak of food poisoning caused by an Enteropathogeic Escherichia coli 479 O115:H19 in Miyagi Prefecture. Jpn. J. Infect. Dis. 58, 189-190.

480 Silva, L.E., Souza, T.B., Silva, N.P., Scaletsky, I.C., 2014. Detection and genetic analysis of the enteroaggregative Escherichia coli heat-stable enterotoxin (EAST1) gene in clinical isolates

Sirikaew S., Patungkaro W., Rattanachuay P., Sukkua K., Sukhumungoon P., 2014. Enterotoxigenic Escherichia coli O169:HUT from a diarrheal patient: Phylogenetic group and antimicrobial susceptibility. Southeast Asian J. Trop. Med. Public Health. 45, 1376-1384.

Siriwan-Sirikaew., Rattanachuay P., Nakaguchi Y., Sukhumungoonl P., 2015. Immuno-magnetic isolation, characterization and genetic relationship of Escherichia coli O26 from raw meats, Hat Yai City, Songkhla, Thailand. Southeast Asian J. Trop. Med. Public Health. 46, 241-253.

Solomakos N., Govaris A., Angelidis A.S., Pournaras S., Burriel A.R., Kritas S.K., Papageorgiou D.K., 2009. Occurrence, virulence genes and antibiotic resistance of Escherichia coli 0157 isolated from raw bovine, caprine and ovine milk in Greece. Food Microbiol. 26, 865-871. enteropathogenic Escherichia coli strains from Australian patients. Diagn. Microbiol. Infect. 
Dis. 75, 320-324.

495 Teophilo G.N., dos Fernandes Vieira R.H., dos Prazeres Rodrigues D., Menezes F.G., 2002.

496 Escherichia coli isolated from seafood: Toxicity and plasmid profiles. Int. Microbiol. 5, 11-

$497 \quad 14$.

498 Terajima J., Izumiya H., Iyoda S., Tamura K., Watanabe H., 1999. Detection of a multi-

499 prefectural E coli O157:H7 outbreak caused by contaminated Ikura-Sushi ingestion. Jpn. J.

$500 \quad$ Infect. Dis. 52, 52-53.

501 Tozzoli R., Scheutz F., 2014. Diarrhoeagenic Escherichia coli infections in humans. In: Morabito

502 S. (Ed.), Pathogenic Escherichia coli. Caister Academic Press, Norfolk, UK, pp. 1-18.

503 Wang L., Wakushima M., Aota T., Yoshida Y., Kita T., Maehara T., Ogasawara J., Choi C.,

504 Kamata Y., Hara-Kudo Y., Nishikawa Y., 2013. Specific properties of Enteropathogenic

505 Escherichia coli isolates from diarrheal patients and comparison to strains from foods and

506 fecal specimens from cattle, swine, and healthy carriers in Osaka City, Japan. Appl. Environ.

$507 \quad$ Microbiol. 79, 1232-1240.

508 Wang L., Wakushima M., Kamata Y., Nishikawa Y., 2011. Exhaustive isolation of diarrhoeagenic

$509 \quad$ Escherichia coli by a colony hybridization method using hydrophobic grid-membrane filters

510 in combination with multiplex real-time PCR. Lett. Appl. Microbiol. 53, 264-270.

511 Yagi T., Wachino J., Kurokawa H., Suzuki S., Yamane K., Doi Y., Shibata N., Kato H.,

512 Shibayama K., Arakawa Y., 2005. Practical methods using boronic acid compounds for

513 identification of class C $\beta$-beta-lactamase-producing Klebsiella pneumoniae and Escherichia

$514 \quad$ coli. J. Clin. Microbiol. 43, 2551-2558.

515 Yu T., Zhang J., Jiang X., Wu J., Dai Z., Wu Z., Liang Y., Wang X., 2016. Characterization and

516 horizontal transfer of class 1 integrons in Escherichia coli isolates from cooked meat 
517 products. J. Infect. Dev. Ctries. 10, 68-73.

518 Zhou, Z., Ogasawara, J., Nishikawa, Y., Seto, Y., Helander, A., Hase, A., Iritani, N., Nakamura,

519 H., Arikawa, K., Kai, A., Kamata, Y., Hoshi, H., Haruki, K., 2002. An outbreak of

520 gastroenteritis in Osaka, Japan due to Escherichia coli serogroup O166:H15 that had a coding

521 gene for enteroaggregative E. coli heat-stable enterotoxin 1 (EAST1). Epidemiol. Infect. 128,

$522 \quad 363-371$.


Table 1. Isolation of DEC from food samples*

\begin{tabular}{|c|c|c|c|c|c|c|c|}
\hline \multirow[b]{2}{*}{$\mathrm{DEC}$} & \multicolumn{7}{|c|}{ Number $(\%)$ of DEC strains } \\
\hline & $\begin{array}{c}\text { Total } \\
(\mathrm{n}=333)\end{array}$ & $\begin{array}{l}\text { Beef } \\
(\mathrm{n}=32)\end{array}$ & $\begin{array}{c}\text { Pork } \\
(\mathrm{n}=28)\end{array}$ & $\begin{array}{l}\text { Poultry } \\
(n=20)\end{array}$ & $\begin{array}{c}\text { Fish } \\
(n=136)\end{array}$ & $\begin{array}{l}\text { Fruits and vegetables } \\
\qquad(\mathrm{n}=66)\end{array}$ & $\begin{array}{l}\text { RTE foods } \\
\quad(n=51)\end{array}$ \\
\hline EAST1EC & $62(19)^{\S}$ & $9(28)$ & $15(54)$ & $20(100)$ & $7(5.1)$ & $8(12)$ & $3(5.9)$ \\
\hline EPEC $^{\#}$ & $16(4.8)$ & $1(3.1)$ & $5(18)$ & $5(25)$ & $5(3.7)$ & & \\
\hline STEC & $1(0.3)$ & $1(3.1)$ & & & & & \\
\hline EAEC & $1(0.3)$ & & & & $1(0.7)$ & & \\
\hline ETEC & $2(0.6)$ & & & $1(5)$ & & & $1(2.0)$ \\
\hline Total samples ${ }^{\ddagger}$ & 64 (19) & $9(28)^{\mathrm{ac} \hbar}$ & $15(54)^{\mathrm{a}}$ & $20(100)^{b}$ & $9(6.6)^{\mathrm{d}}$ & $8(12)^{\mathrm{cd}}$ & $3(5.9)^{\mathrm{d}}$ \\
\hline Total $^{\dagger}$ & 82 & 11 & 20 & 26 & 13 & 8 & 4 \\
\hline
\end{tabular}

${ }^{*}$ DEC: diarrheogenic E. coli; EAST1EC: EAEC heat-stable enterotoxin 1 possessing E. coli; EPEC: enteropathogenic E. coli; STEC: Shiga toxin-producing $E$. coli; EAEC: enteroaggregative $E$. coli; ETEC: enterotoxigenic $E$. coli; RTE foods: ready to eat foods

$\S$ Numbers in brackets mean the percentage of DEC from food samples

\# Phylogroups of the strains are as follows: 1 B1 strain from beef; 3 B1, 1 B2, and 1 D strains from pork; 3 A, 1 B1, and 1 D strains from poultry;

$1 \mathrm{~A}, 2 \mathrm{~B} 1,1 \mathrm{~B} 2$, and $1 \mathrm{D}$ strains from fish

${ }^{\ddagger}$ Number of samples that DEC strains were isolated from

$\dagger$ Number of DEC strains

$\$$ Treatments with different lower case letters (a-d) in the same line are significantly different $(P<0.05)$ 
Table 2. Serotypes of DEC isolated from different sources of food*

\begin{tabular}{|c|c|c|c|c|c|}
\hline Serotype & Number of isolates & Serotype & Number of isolates & Serotype & Number of isolates \\
\hline OUT:HUT & 20 (1 ETEC, 3 EPEC) $\#$ & O8:HUT & 1 & O91:H21 & $1(\mathrm{STEC})$ \\
\hline OUT:HNM & 4 (1 EPEC) & O8:H16 & 1 & O103:HUT & 1 (EPEC) \\
\hline OUT:H2 & 1 & O8:H40 & 2 (1 EPEC) & $\mathrm{O} 103: \mathrm{H} 2$ & 1 (EPEC) \\
\hline OUT:H6 & 2 & O15:H6 & 1 & O115:HUT & 1 (EPEC) \\
\hline OUT:H7 & 1 & O18:HUT & 1 & O119:H45 & 1 \\
\hline OUT:H10 & 2 (1 EPEC) & O18:H9 & 1 & O124:HUT & 1 \\
\hline OUT:H12 & 4 (2 EPEC) & O18:H12 & 2 & O126:HUT & 2 (1 EAEC) \\
\hline OUT:H16 & 10 (3 EPEC) & O20:HUT & 1 (EPEC) & O127a:HUT & 1 (ETEC) \\
\hline OUT:H34 & 3 (1 EPEC) & O20/157:H12 & 1 & O136:H12 & 1 \\
\hline OUT:H40 & 1 & O27:HNM & 1 & O148:HUT & 1 \\
\hline OUT:H41 & 1 & O28ac:H16 & 1 & O152:H12 & 1 \\
\hline OUT:H42 & 1 & O63:H42 & 1 & O153:H9 & 1 \\
\hline OUT:H45 & 1 & O74:HUT & 1 & O158:H9 & 1 \\
\hline O1:HUT & 1 & O91:HUT & 1 & & \\
\hline
\end{tabular}

* DEC: diarrheogenic E. coli; OUT: O antisera untypeable; HUT: H antisera untypeable; HNM: non-motile strains

\# Numbers and the pathogenic types of DEC were shown in brackets, and remains are EAST1EC. 
Table 3. Distribution of phylogenetic groups among 82 DEC isolates obtained from different food sources*

\begin{tabular}{ccccc}
\hline \multirow{2}{*}{ Pathotypes } & \multicolumn{4}{c}{ Number (\%) of DEC strains } \\
\cline { 2 - 5 } & A & B1 & B2 & D \\
\hline EAST1EC $(n=62)$ & $31(50)^{\#}$ & $18(29)$ & $3(5)$ & $10(16)$ \\
EPEC $(n=16)$ & $4(25)$ & $7(44)$ & $2(13)$ & $3(19)$ \\
STEC $(n=1)$ & & $1(100)$ & \\
EAEC $(n=1)$ & & $1(100)$ & \\
ETEC $(n=2)$ & $2(100)$ & & & $13(16)$ \\
Total $(\mathrm{n}=82)$ & $37(45)$ & $27(33)$ & $5(6)$ &
\end{tabular}

* DEC: diarrheogenic E. coli; RTE foods: ready to eat foods

\# Numbers in brackets mean the percentage of DEC from food samples 
Table 4. Antimicrobial resistance patterns of DEC isolates obtained from different food sources *

\begin{tabular}{|c|c|c|c|c|c|c|c|}
\hline \multirow[b]{2}{*}{ Resistance pattern ( 29 profiles) } & \multicolumn{7}{|c|}{ Number (\%) and phylogenetic groups of DEC strains } \\
\hline & $\begin{array}{l}\text { Total } \\
(\mathrm{n}=82)\end{array}$ & $\begin{array}{l}\text { Beef } \\
(\mathrm{n}=11)\end{array}$ & $\begin{array}{l}\text { Pork } \\
(\mathrm{n}=20)\end{array}$ & $\begin{array}{l}\text { Poultry } \\
(\mathrm{n}=26)\end{array}$ & $\begin{array}{l}\text { Fish } \\
(\mathrm{n}=13)\end{array}$ & $\begin{array}{c}\text { Fruits and } \\
\text { vegetables }(n=8)\end{array}$ & $\begin{array}{l}\text { RTE foods } \\
\quad(\mathrm{n}=4)\end{array}$ \\
\hline AMP & 2 & $1, \mathrm{~B} 1$ & & $1, \mathrm{D}$ & & & \\
\hline CEP & 3 & & & & 2, A,B1 & $1, \mathrm{~B} 1$ & \\
\hline TET & 6 & & 2, $\mathrm{AB} 1$ & $3, \mathrm{AAB} 1$ & & & $1, \mathrm{~A}$ \\
\hline NAL & 2 & & & $2, \mathrm{AA}$ & & & \\
\hline CHL & 1 & & $1, \mathrm{~A}$ & & & & \\
\hline SXT & 1 & & $1, \mathrm{~B} 1$ & & & & \\
\hline Subtotal & $15(18)^{\dagger}$ & & & & & & \\
\hline AMP-TET & 1 & & & $1, \mathrm{~A}$ & & & \\
\hline GEN-TET & 1 & & & $1, \mathrm{D}$ & & & \\
\hline TET-NAL & 6 & $1, \mathrm{D}$ & & 4, AAAD & & & $1, \mathrm{D}$ \\
\hline TET-SXT & 5 & & 4, AAAB2 & $1, \mathrm{~A}$ & & & \\
\hline Subtotal & $13(16)$ & & & & & & \\
\hline AMP-CEP-TET & 1 & & $1, \mathrm{D}$ & & & & \\
\hline AMP-TET-NAL & 2 & $1, \mathrm{~A}$ & & & $1, \mathrm{D}$ & & \\
\hline CEP-TET-NAL & 2 & $1, \mathrm{~A}$ & & $1, \mathrm{~A}$ & & & \\
\hline Subtotal & $5(6.1)$ & & & & & & \\
\hline AMP-AMC-CEP-TET & 1 & & & & $1, \mathrm{~A}$ & & \\
\hline AMP-AMC-CEP-FOX & 1 & & & & $1, \mathrm{~B} 1$ & & \\
\hline AMP-CEP-TET-NAL & 1 & & & $1, \mathrm{~B} 1$ & & & \\
\hline AMP-CEP-TET-SXT & 1 & & $1, \mathrm{D}$ & & & & \\
\hline AMP-GEN-TET-SXT & 1 & & $1, \mathrm{~A}$ & & & & \\
\hline AMP-TET-NAL-SXT & 1 & & & $1, \mathrm{~A}$ & & & \\
\hline AMP-TET-CHL-SXT & 1 & & & $1, \mathrm{~B} 1$ & & & \\
\hline
\end{tabular}




\begin{tabular}{|c|c|c|c|c|c|c|}
\hline CEP-TET-NAL-SXT & 1 & & & $1, \mathrm{~B} 1$ & & \\
\hline GEN-TET-CIP-NAL & 1 & & & $1, \mathrm{~B} 1$ & & \\
\hline TET-NAL-CHL-SXT & 1 & $1, \mathrm{~B} 1$ & & & & \\
\hline Subtotal & $10(12)$ & & & & & \\
\hline AMP-AMC-CEP-TET-SXT & 1 & & & $1, \mathrm{~A}$ & & \\
\hline AMP-CEP-TET-CIP-NAL & 2 & & $1, \mathrm{~B} 1$ & $1, \mathrm{~B} 1$ & & \\
\hline AMP-TET-CIP-NAL-CHL & 1 & & & $1, \mathrm{~B} 1$ & & \\
\hline AMP-TET-NAL-CHL-SXT & 1 & $1, \mathrm{D}$ & & & & \\
\hline Subtotal & $5(6.1)$ & & & & & \\
\hline AMP-GEN-TET-CIP-NAL-SXT & 1 & & & $1, \mathrm{~A}$ & & \\
\hline Subtotal & $1(1.2)$ & & & & & \\
\hline $\begin{array}{l}\text { AMP-AMC-CEP-CRO-FOX-TET-NAL- } \\
\text { CHL-SXT }\end{array}$ & 1 & $1, \mathrm{~A}$ & & & & \\
\hline Subtotal & $1(1.2)$ & & & & & \\
\hline Total & $50(61)$ & $7(64)^{\mathrm{abc} \ddagger}$ & $12(60)^{\mathrm{a}}$ & $23(88)^{\mathrm{b}}$ & $5(38)^{\mathrm{ac}}$ & $2(50)^{\mathrm{abc}}$ \\
\hline
\end{tabular}


Table 5. Antimicrobial resistance rate of DEC isolates obtained from different food sources*

\begin{tabular}{|c|c|c|c|c|c|c|c|}
\hline \multirow{2}{*}{$\begin{array}{l}\text { Antimicrobial } \\
\text { resistance }\end{array}$} & \multicolumn{7}{|c|}{ Number $(\%)$ of DEC strains } \\
\hline & $\begin{array}{l}\text { Total } \\
(\mathrm{n}=82)\end{array}$ & $\begin{array}{l}\text { Beef } \\
(\mathrm{n}=11)\end{array}$ & $\begin{array}{l}\text { Pork } \\
(\mathrm{n}=20)\end{array}$ & $\begin{array}{l}\text { Poultry } \\
(n=26)\end{array}$ & $\begin{array}{l}\text { Fish } \\
(\mathrm{n}=13)\end{array}$ & $\begin{array}{c}\text { Fruits and } \\
\text { vegetables }(n=8)\end{array}$ & $\begin{array}{l}\text { RTE foods } \\
\quad(\mathrm{n}=4)\end{array}$ \\
\hline AM & $20(24)^{\dagger}$ & $4(36)$ & $4(20)$ & $9(35)$ & $3(23)$ & & \\
\hline AMC & $4(4.9)$ & $1(9.1)$ & & $1(3.8)$ & $2(15)$ & & \\
\hline $\mathrm{CF}$ & $15(18)$ & $2(18)$ & $3(15)$ & $5(19)$ & $4(31)$ & $1(13)$ & \\
\hline CRO & $1(1.2)$ & $1(9.1)$ & & & & & \\
\hline FOX & $2(2.4)$ & $1(9.1)$ & & & $1(7.7)$ & & \\
\hline \multicolumn{8}{|l|}{ ATM } \\
\hline GM & $4(4.9)$ & & $1(5.0)$ & $3(12)$ & & & \\
\hline $\mathrm{Te}$ & $40(49)$ & $6(55)^{\mathrm{ac} \hbar}$ & $10(50)^{\mathrm{ac}}$ & $20(77)^{\mathrm{a}}$ & $2(15)^{\mathrm{bc}}$ & $0(0)^{\mathrm{b}}$ & $2(50)^{\mathrm{abc}}$ \\
\hline CIP & $5(6.1)$ & & $1(5.0)$ & $4(15)$ & & & \\
\hline NA & $23(28)$ & $6(55)^{\mathrm{a}}$ & $1(5.0)^{\mathrm{b}}$ & $14(54)^{\mathrm{a}}$ & $1(7.7)^{b}$ & $0(0)^{\mathrm{b}}$ & $1(25)^{\mathrm{ab}}$ \\
\hline $\mathrm{C}$ & $6(7.3)$ & $3(27)$ & $1(5.0)$ & $2(7.7)$ & & & \\
\hline SXT & $16(20)$ & $3(27)^{\mathrm{ab}}$ & $7(35)^{\mathrm{a}}$ & $6(23)^{\mathrm{ab}}$ & $0(0)^{\mathrm{b}}$ & & \\
\hline
\end{tabular}

${ }^{*}$ DEC: diarrheogenic E. coli; RTE foods: ready to eat foods; AMP: Ampicillin, AMC: Amoxicillin - Clavulanic acid, CEP: Cephalothin, CRO:

Ceftriaxion, FOX: Cefoxitin, ATM: Aztreonam, GEN: Gentamicin, TET: Tetracycline, CIP: Ciprofloxacin, NAL: Nalidixic acid, CHL:

Chloramphenicol, SXT: Sulfamethoxazole - Trimethoprim

${ }^{\dagger}$ Numbers in brackets mean the percentage of DEC from food samples

* Treatments with different lower case letters $(\mathrm{a}-\mathrm{c})$ in the same line are significantly different $(P<0.05)$ 
Table 6. Antimicrobial resistance rate of DEC isolates*

Number (\%) of DEC strains

\begin{tabular}{|c|c|c|c|c|c|c|}
\hline Antimicrobial resistance & $\begin{array}{c}\text { Total } \\
(n=82)\end{array}$ & $\begin{array}{c}\begin{array}{c}\text { EAST1EC } \\
(\mathrm{n}=62)\end{array} \\
\end{array}$ & $\begin{array}{l}\text { EPEC } \\
(n=16)\end{array}$ & $\begin{array}{l}\text { STEC } \\
(\mathrm{n}=1)\end{array}$ & $\begin{array}{c}\text { EAEC } \\
(\mathrm{n}=1)\end{array}$ & $\begin{array}{c}\text { ETEC } \\
(\mathrm{n}=2)\end{array}$ \\
\hline Resistant to 1 antimicrobial & $15(18)^{\#}$ & $10(16)$ & $4(25)$ & & & $1(50)$ \\
\hline Resistant to 2 antimicrobials & $13(16)$ & $9(15)$ & $3(19)$ & & & $1(50)$ \\
\hline Resistant to 2 or less antimicrobials & $28(34)$ & $19(31)$ & $7(44)$ & 0 & 0 & $2(100)$ \\
\hline Resistant to 3 antimicrobials & $5(6.1)$ & $4(6.5)$ & $1(6.3)$ & & & \\
\hline Resistant to 4 antimicrobials & $10(12)$ & $8(13)$ & $1(6.3)$ & & $1(100)$ & \\
\hline Resistant to 5 antimicrobials & $5(6.1)$ & $5(8.1)$ & & & & \\
\hline Resistant to 6 antimicrobials & $1(1.2)$ & $1(1.6)$ & & & & \\
\hline Resistant to 9 antimicrobials & $1(1.2)$ & $1(1.6)$ & & & & \\
\hline Resistant to 3 or more antimicrobials & $22(27)$ & $19(31)$ & $2(13)$ & 0 & $1(100)$ & 0 \\
\hline Resistant to antimicrobials & $50(61)$ & $38(61)$ & $9(56)$ & 0 & $1(100)$ & $2(100)$ \\
\hline
\end{tabular}

${ }^{*}$ DEC: diarrheogenic E. coli; EAST1EC: EAEC heat-stable enterotoxin 1 possessing E. coli; EPEC: enteropathogenic E. coli; STEC: Shiga toxin-producing $E$. coli; EAEC: enteroaggregative $E$. coli; ETEC: enterotoxigenic E. coli

\# Numbers in brackets mean the percentage of DEC from food samples 
Table 7. Antimicrobial resistance rate of DEC isolates in each phylogenetic group obtained from different food sources*

\begin{tabular}{|c|c|c|c|c|c|c|c|}
\hline \multirow[b]{2}{*}{$\begin{array}{l}\text { Phylogenetic } \\
\text { group }\end{array}$} & \multicolumn{7}{|c|}{ Number (\%) of DEC strains } \\
\hline & $\begin{array}{l}\text { Total } \\
(\mathrm{n}=82)\end{array}$ & $\begin{array}{c}\text { Beef } \\
(\mathrm{n}=11)\end{array}$ & $\begin{array}{l}\text { Pork } \\
(\mathrm{n}=20)\end{array}$ & $\begin{array}{l}\text { Poultry } \\
(n=26)\end{array}$ & $\begin{array}{c}\text { Fish } \\
(\mathrm{n}=13)\end{array}$ & $\begin{array}{l}\text { Fruits and vegetables } \\
\qquad(\mathrm{n}=8)\end{array}$ & $\begin{array}{l}\text { RTE foods } \\
\quad(\mathrm{n}=4)\end{array}$ \\
\hline$A(n=37)$ & $25(68)^{\#}$ & $3(60)^{\mathrm{ab} \dagger}$ & $6(60)^{\mathrm{ab}}$ & $13(93)^{\mathrm{a}}$ & $2(50)^{\mathrm{ab}}$ & $0(0)^{\mathrm{b}}$ & $1(50)^{\mathrm{ab}}$ \\
\hline B1 $(n=27)$ & $15(56)$ & $2(50)^{\mathrm{abc}}$ & $3(50)^{\mathrm{abc}}$ & $7(100)^{\mathrm{a}}$ & $2(40)^{\mathrm{b}}$ & $1(25)^{\mathrm{bc}}$ & $0(0)^{\mathrm{abc}}$ \\
\hline B2 $(n=5)$ & $1(20)$ & & $1(50)$ & & & & \\
\hline $\mathrm{D}(\mathrm{n}=13)$ & $9(69)$ & $2(100)$ & $2(100)$ & $3(60)$ & $1(50)$ & & $1(100)$ \\
\hline Total & $50(61)$ & $7(64)$ & $12(60)$ & $23(88)$ & $5(38)$ & $1(13)$ & $2(50)$ \\
\hline
\end{tabular}

* DEC: diarrheogenic E. coli; RTE foods: ready to eat foods

\# Numbers in brackets mean the percentage of DEC from food samples

$\dagger$ Treatments with different lower case letters $(\mathrm{a}-\mathrm{c})$ in the same line are significantly different $(P<0.05)$ 


\section{Figure legends}

Fig. 1. Dendrogram of DEC was investigated in this study by GECM10. Four pairs of isolates that showed the identical MLVA loci pattern are marked in black squares. Three strains marked with underline were performed with ESBL and AmpC Producing Conformation Test. EAST1EC was represented by EASTEC in this figure.

Fig. 2. Population modelling using the Minimum Spanning Tree (MST) Method on a set of 82 DEC isolates. Each circle is noted with source and phylogenetic group while the different color of the circles indicates the antimicrobial resistant property of each strain. B: beef, P: pork, C: chicken?, F: fish, V: Fruits and vegetables, R: RTE foods. Black circle: resistant to 1 antimicrobial agent, blue circle: 2 agents, green circle: 3 agents, yellow circle: 4 agents, yellow triangle: 5 agents, yellow star: 6 agents, red circle: 9 agents, original purple circle with black edging: susceptible strains. 
Peassonccareation 2.12

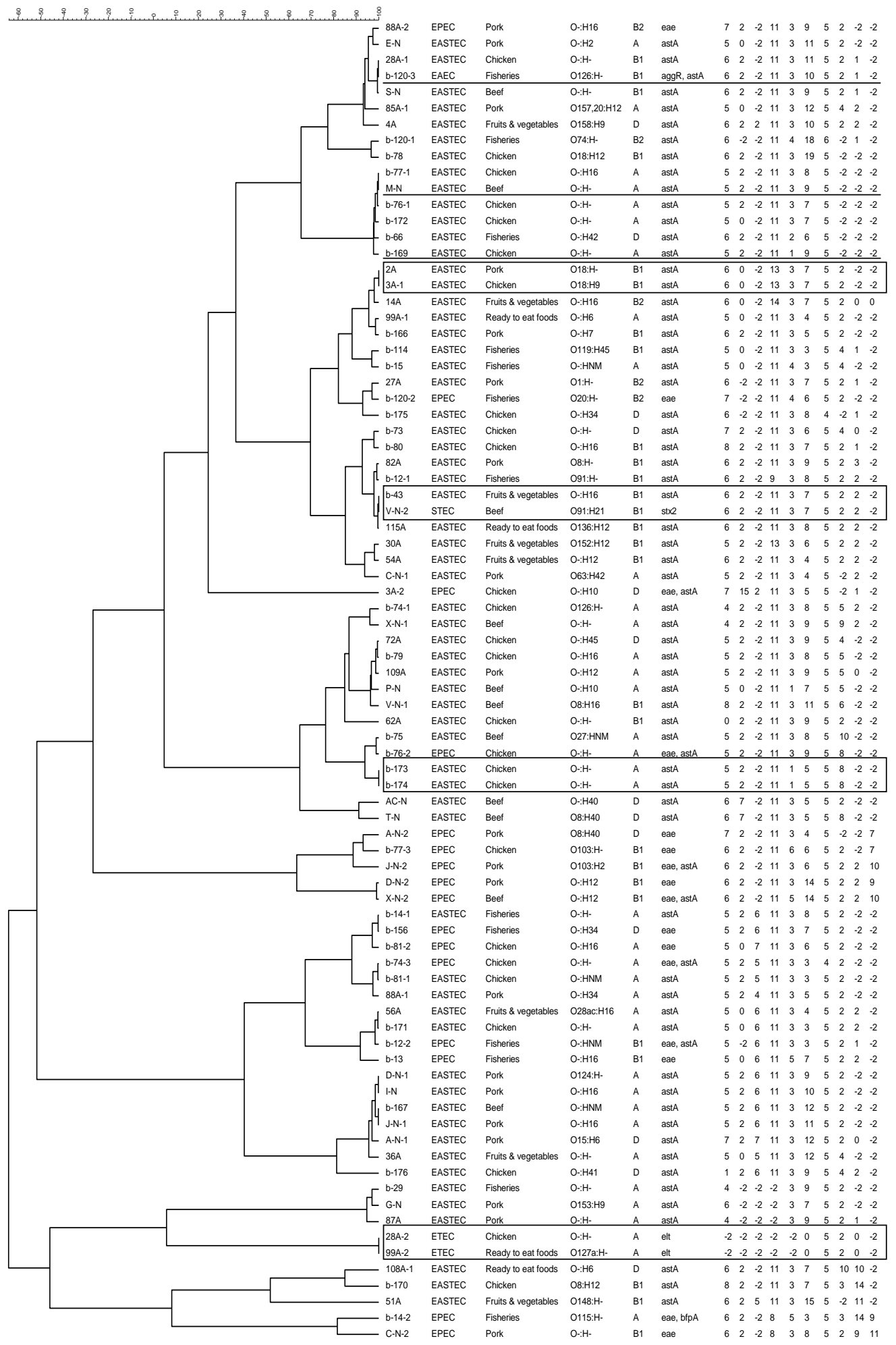

Fig. 1 


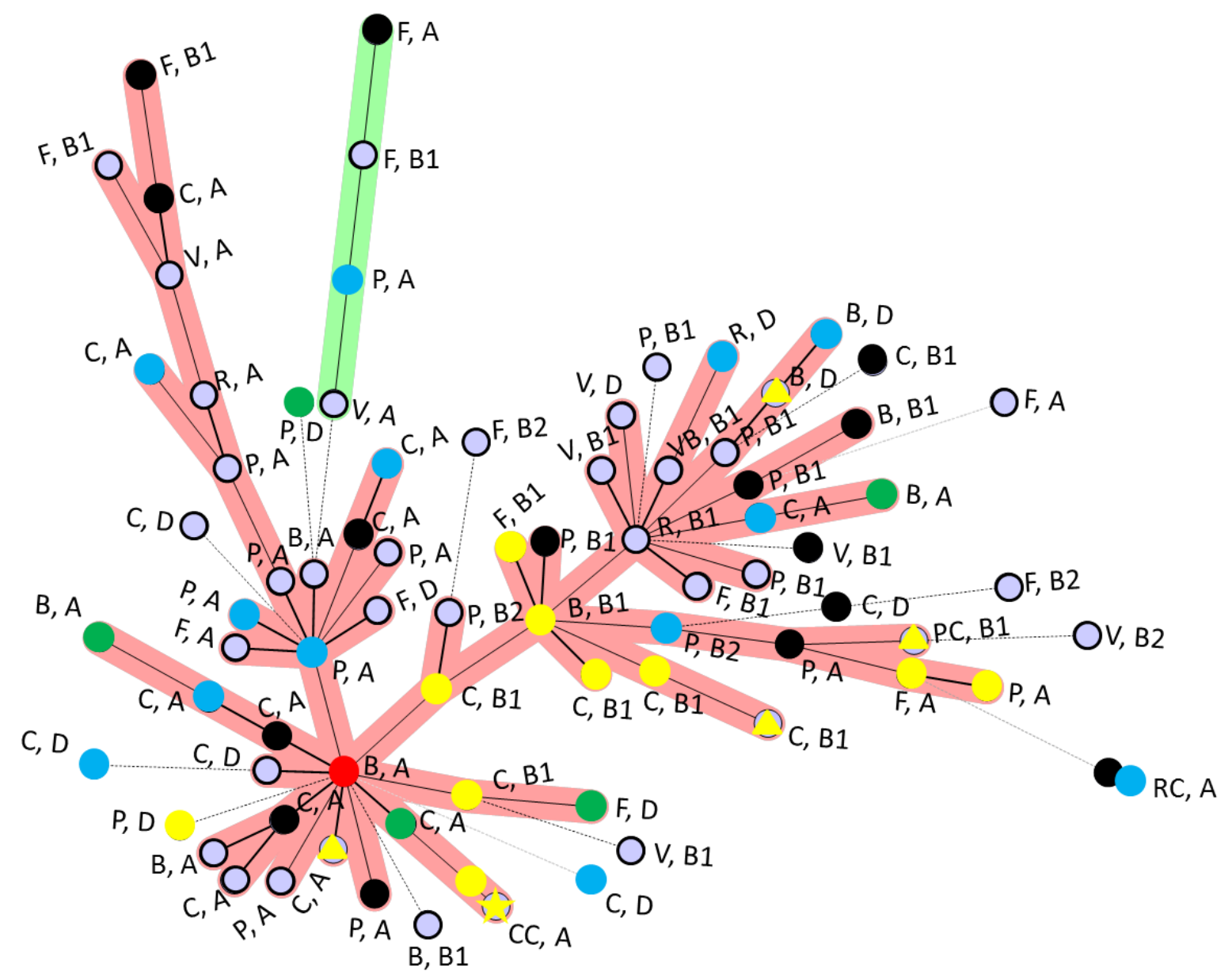

Fig. 2 